\title{
The Prognostic Significance of P-Cadherin in Infiltrating Ductal Breast Carcinoma
}

\author{
Carlos Gamallo, M.D., Gema Moreno-Bueno, Ph.D., David Sarrió, Ph.D., Francisco Calero, M.D., \\ David Hardisson, M.D., José Palacios, M.D. \\ Servicio de Anatomía Patológica, Hospital Universitario de La Princesa (CG), Programa de Patología \\ Molecular, Centro Nacional de Investigaciones Oncológicas (CNIO) Carlos III (GMB, DS, JP), and \\ Departamentos de Obstetricia y Ginecología (FC) and Anatomía Patológica (DH), Hospital Universitario \\ La Paz, Madrid, Spain
}

We have immunohistochemically investigated $P$-cadherin (P-CD) expression in a series of 210 infiltrating ductal carcinomas (IDC) in an attempt to assess the biological and prognostic relevance of P-CD in patients harboring IDCs. Although only $74 / 210$ (35\%) of IDCs expressed P-CD in $>5 \%$ of tumor cells (P-CD-positive carcinomas), categorical analyses revealed that $\mathrm{P}$-CD-positive IDCs were larger ( $26 \pm 21 \mathrm{~cm}$ versus $22 \pm 11 \mathrm{~cm}, P=.0568)$, of higher histological grade $(P=.0001)$, and had more lymph node metastases $(P=.0327)$ than $P-C D-$ negative breast carcinomas. In addition, $P$-CD-positive tumors were negative for estrogen $(P=.0001)$ and progesterone receptors $(P=.0001)$ and showed reduced E-cadherin expression $(P=.0276)$ more frequently than P-CD-negative tumors. Univariate analysis carried out in 171 patients demonstrated that P-CD expression was also an indicator of poor prognosis $\left(\chi^{2}=8.292, P=.004\right)$, extent of lymph node metastasis $\left(\chi^{2}=\mathbf{2 0 . 8 5 4}, P=.0000\right)$, histological grade $\left(\chi^{2}=12.908, P=.0016\right)$, and negative progesterone receptors $\left(\chi^{2}=4.116, P=.042\right)$. However, only histological grade and nodal metastases emerged as independent prognostic markers in the multivariate analysis. These results suggest that although P-CD expression may be involved in the progression of IDCs, its value as an independent prognostic factor remains to be established.

Copyright $\odot 2001$ by The United States and Canadian Academy of Pathology, Inc.

VOL. 14, NO. 7, P. 650, 2001 Printed in the U.S.A.

Date of acceptance: February 27, 2001.

Supported by research grants 98/0151 from the Fondo de Investigaciones Científicas de la Seguridad Social, CAM08.1/0020/1997 from Comunidad Autonoma de Madrid, and SAF 98-0085-C03-03 from the Ministerio de Educación y Cultura, Spain.

Address correspondence to: José Palacios, M.D., Programa de Patología Molecular, Centro Nacional de Investigaciones Oncológicas Carlos III, Instituto de Salud Carlos III, Ctra Majadahonda-Pozuelo, Km 2. 280220 Majadahonda Madrid, Spain; e-mail: jpalacios@cnio.es; fax: 34-91509-70-52.
KEY WORDS: Breast cancer, E-cadherin, P-cadherin, Prognosis Tumor progression.

Mod Pathol 2001;14(7):650-654

E- and P-cadherins (E- and P-CD, respectively) play important roles in maintaining the structural integrity of epithelial tissues. However, the expression pattern of both cadherins is very distinct in most tissues' cells (1-3). For example, P-CD expression is restricted to the basal or lower layers of stratified epithelia (1), suggesting that in addition to maintaining cellular adhesion, P-CD may have other functions in differentiation and cell growth. In adult human mammary gland, P-CD expression is characteristic of myoepithelial cells, whereas E-CD is expressed in epithelial cells $(1,4-6)$. Experimental studies have also suggested a fundamental morphoregulatory role for P-CD during breast development. P-CD expression is characteristic of the stem cells (cap cells), the precursor of myoepithelial cells, which do not express estrogen receptors and have a high proliferation rate and low frequency of apoptosis (7). In addition, P-CD-deficient mice have anomalous mammary gland development (8).

The role of $\mathrm{P}-\mathrm{CD}$ in pathology is poorly understood. Up-regulation of P-cadherin has been demonstrated in inflammatory bowel diseases such as Crohn's disease and ulcerative colitis, in which there was also down-regulation of E-CD (9). Surprisingly, and in contrast with the numerous published reports dealing with E-CD in human neoplasia, very few studies have analyzed the P-CD expression pattern in large tumor series. In addition, the frequency and biological significance of $\mathrm{P}-\mathrm{CD}$ expression varies greatly with the primary tumor site $(1,10-14)$. Aberrant P-CD expression is related with cell proliferation and dedifferentiation in breast cancer (5). In addition, it has recently been reported that $\mathrm{P}-\mathrm{CD}$ expression is an independent prognostic marker of poor outcome in breast carcinoma (6). In this study, we analyze the P-CD 
expression pattern in a large series of infiltrating ductal carcinomas (IDCs) and its relationship with clinicopathological features, E-CD expression, and survival in an attempt to better understand the clinical relevance of P-CD in breast cancer.

\section{MATERIALS AND METHODS}

\section{Clinicopathological Data and E-Cadherin Expression}

Material for this study was obtained from 210 primary breast carcinomas selected from a cohort of 230 cases in which clinicopathological features (age, tumor size, grade, nodal status, and hormonal receptor status) and E-CD expression pattern had previously been reported (15). Briefly, the series consisted of 41 (19.5\%) Grade 1, 79 (37.6\%) Grade 2, and 90 (42.9\%) Grade 3 infiltrating ductal carcinomas. Grading of the tumors was based on the recommendations made by Elston (16). The mean age at presentation was $56 \pm 11.8$ years (range, 27 to $83 \mathrm{y}$ ). The mean tumor size was $2.25 \mathrm{~cm}$ (range, 0.6 to 18). Lymph node dissection was performed in 198 patients. Of these patients, $88(44.6 \%)$ were N0, 71 (35.9\%) were N1, and 39 (19.5\%) were N2. Estrogen and progesterone receptors (ER and PgR) were examined in frozen sections using ER-ICA and PgRICA Kits (Abbot Laboratories, North Chicago, IL). Hormonal receptor status was assessed with the Quantitative Estrogen Progesterone application of the CAS 200 Analyzer (Cell Analysis System, Lombard, IL). A tumor was considered to be positive for ER and/or PgR when the positive nuclear area was $\geq 10 \%$ of the total nuclear area. Hormone receptor content was evaluated in 204 tumors: 121 cases (59.3\%) were ER positive, and 102 cases (50\%) were PgR positive. E-CD expression was evaluated in frozen sections in all but one carcinoma. E-CD expression was estimated semiquantitatively using a composite score obtained by adding the values of the immunoreaction intensity and the relative abundance of E-CD immunoreactive cells. Briefly, the intensity was graded from 0 (equivalent to that of background staining of the acellular stroma) to +3 (intense stain equivalent to that of normal breast epithelium). The abundance of E-CD positive cells was graded from 0 to $4(0=<5 \%$ positive cells; $1=$ 5 to $25 \% ; 2=26$ to $50 \% ; 3=51$ to $75 \% ; 4=76$ to $100 \%)$. Preserved E-CD expression was considered when the composite score was 6 or 7 (102 cases, $48.8 \%$ in this series).

\section{P-Cadherin Immunohistochemistry}

Immunohistochemistry of P-cadherin was performed by the Envision+/HRP (DAKO A/S, Glostrup, Denmark) method with heat-induced an- tigen retrieval. Mouse anti-human P-cadherin monoclonal antibody (Transduction Laboratories, Lexington, $\mathrm{KY}$ ) was applied at a dilution of 1:200. All studied tumor sections also included normal breast tissue as an internal control for P-CD expression. The primary antibody was omitted in negative controls. Immunohistochemical staining was evaluated independently by two pathologists (CG and JP). A tumor was considered to be $\mathrm{P}-\mathrm{CD}$ positive when at least $5 \%$ of the cells showed P-CD immunostaining.

Contingency tests with Yates correction was used to determine the statistical significance of the relationships between P-CD expression and the factors of tumor grade, lymph node metastasis, hormone receptor content, and E-CD expression. ANOVA was used to investigate differences in tumor size. As measures of prognosis, we examined disease-free survival, defined as the time from diagnosis to first recurrence or last contact (censored), and overall survival, defined as the time from diagnosis to death or last contact (censored). Univariate survival curves were estimated using the method of Kaplan and Meier and compared using the log-rank test. Multivariate analysis was done using the Cox's proportional hazards regression model. Statistical analyses were carried out using JMP (Version 3.0.1, SAS Institute, Cary, NC).

\section{RESULTS}

P-cadherin was observed in myoepithelial cells in normal breast tissue, but not in acinar or ductal epithelial luminal cells (Fig. 1A). P-cadherin expression in $>5 \%$ of tumor cells was observed in 74 IDC (35\%) (P-CD-positive carcinomas). The percentage of positive cells varied from 5 to $100 \%$, but only 35 cases (17\%) showed P-CD immunostaining in

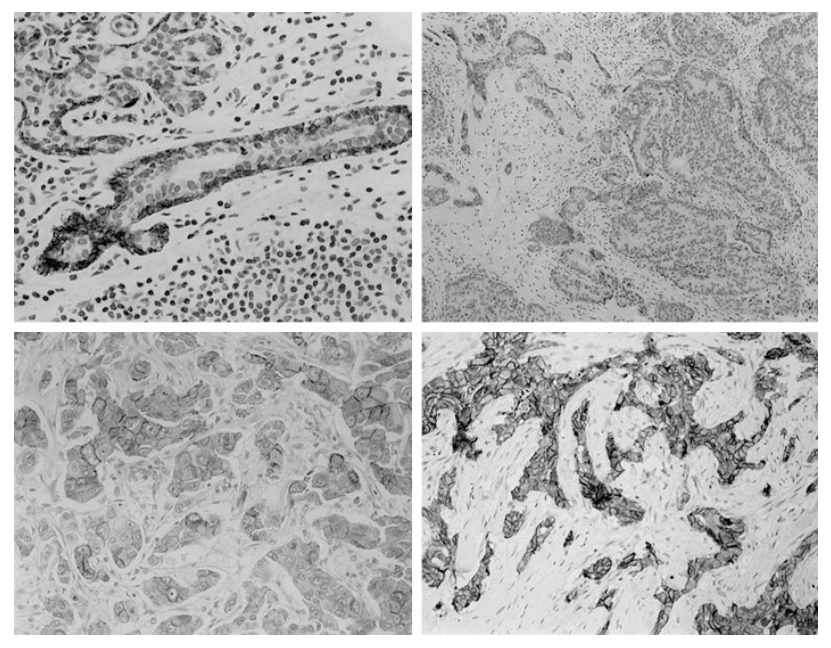

FIGURE 1. P-cadherin expression in normal breast tissue is restricted to myoepithelial cells (A). P-cadherin positivity is observed in residual myoepithelial cells in a P-cadherin-negative breast carcinoma (B). Pcadherin-positive infiltrating ductal carcinomas (C and D). 
$>25 \%$ of neoplastic cells (Fig. 1, B-D). P-cadherinpositive cells were randomly distributed in P-cadherin-positive carcinomas that had a focal immunostaining pattern.

When P-CD expression was correlated with pathological variables, a significant association was found between positive P-CD expression and tumor size, histological grade and number of axillary lymph node metastases (Table 1). P-CD-positive breast carcinomas were larger $(26 \pm 21 \mathrm{~cm}$ versus 22 $\pm 11 \mathrm{~cm}, P=.0568$ ), of higher histological grade, and had more lymph node metastases than was the case in P-CD-negative breast carcinomas.

When comparing P-CD expression with immunohistochemical variables, a significant association was also found with ER, PR and E-CD (Table1). $\mathrm{P}$-CD-positive breast carcinomas were negative for ER and PR and showed reduced E-CD more frequently than P-CD-negative tumors (Table 1).

Survival analysis was carried out on 171 patients. The mean follow-up time in this group was $57.02 \pm$ 22.27 months (range, 7 to 100 months; median follow-up period 63 months). Variables analyzed were age, tumor size, histological grade, hormone receptor status, lymph node metastasis, E- and P-CD expression. There were 63 recurrences and 38 deaths in the cohort. Disease-free survival and overall survival differed significantly between classes of P-CD expression, histological grade, number of lymph node metastasis and progesterone receptors, as revealed Kaplan-Meier plots. The probabilities of disease-free and overall survival were significantly lower for patients with P-CD positive tumors $\left(\chi^{2}=7.296, P=.0069\right.$ and $\chi^{2}=8.292$, $P=.004$ respectively) (Fig. 2) and those with more lymph node metastasis $\left(\chi^{2}=28.501, P=.004\right.$ and $\chi^{2}=20.854, P=.0000$, respectively), higher histological grade $\left(\chi^{2}=12.089, P=.0024\right.$ and $\chi^{2}=$

TABLE 1. Relationships between P-Cadherin Expression and Pathological Features in Infiltrating Ductal Carcinomas

\begin{tabular}{|c|c|c|c|}
\hline & \multicolumn{2}{|c|}{ P-Cadherin Expression } & \multirow{2}{*}{$P$-Value $\left(\chi^{2}\right.$ Test $)$} \\
\hline & Negative, n (\%) & Positive, n (\%) & \\
\hline \multicolumn{4}{|c|}{ Histological grade $(\mathrm{n}=210)$} \\
\hline 1 & $31(75.6)$ & $10(24.4)$ & \\
\hline 2 & 66 (83.5) & $13(16.5)$ & \\
\hline 3 & 39 (43.3) & $51(56.7)$ & .0001 \\
\hline \multicolumn{4}{|c|}{ Lymph node metastasis $(\mathrm{n}=198)$} \\
\hline No & $60(68.2)$ & $28(31.8)$ & \\
\hline N1 & $49(69)$ & $22(31)$ & \\
\hline N2 & $18(46.2)$ & $21(53.8)$ & .0327 \\
\hline \multicolumn{4}{|c|}{ Estrogen receptors $(\mathrm{n}=204)$} \\
\hline Positive & 95 (78.6) & $26(21.4)$ & \\
\hline Negative & $36(43.4)$ & $47(56.6)$ & .0001 \\
\hline \multicolumn{4}{|c|}{ Progesterone receptors $(\mathrm{n}=204)$} \\
\hline Positive & $83(81.4)$ & 19 (18.6) & \\
\hline Negative & $48(47.1)$ & $54(52.9)$ & .0001 \\
\hline \multicolumn{4}{|c|}{ E-cadherin expression $(n=209)$} \\
\hline Preserved & $74(72.6)$ & $28(27.4)$ & \\
\hline Reduced & $61(57)$ & $46(43)$ & .0276 \\
\hline
\end{tabular}

$12.908, P=.0016$, respectively) and who were PgRnegative $\left(\chi^{2}=6.456, P=.006\right.$ and $\chi^{2}=4.116, P=$ .042 , respectively). However, the Cox multivariate analysis identified lymph node metastasis and histological grade as the only independent prognostic factors for disease-free survival $\left(\chi^{2}=21.231, P=\right.$ .0000 and $\chi^{2}=7.96, P=.0187$, respectively) and overall survival $\left(\chi^{2}=15.346, P=.0005\right.$ and $\chi^{2}=$ 9.944, $P=.0069$, respectively).

\section{DISCUSSION}

In this study we observed that although P-CD was not expressed in normal epithelial breast tissue, a subset of IDCs showed aberrant P-CD expression,
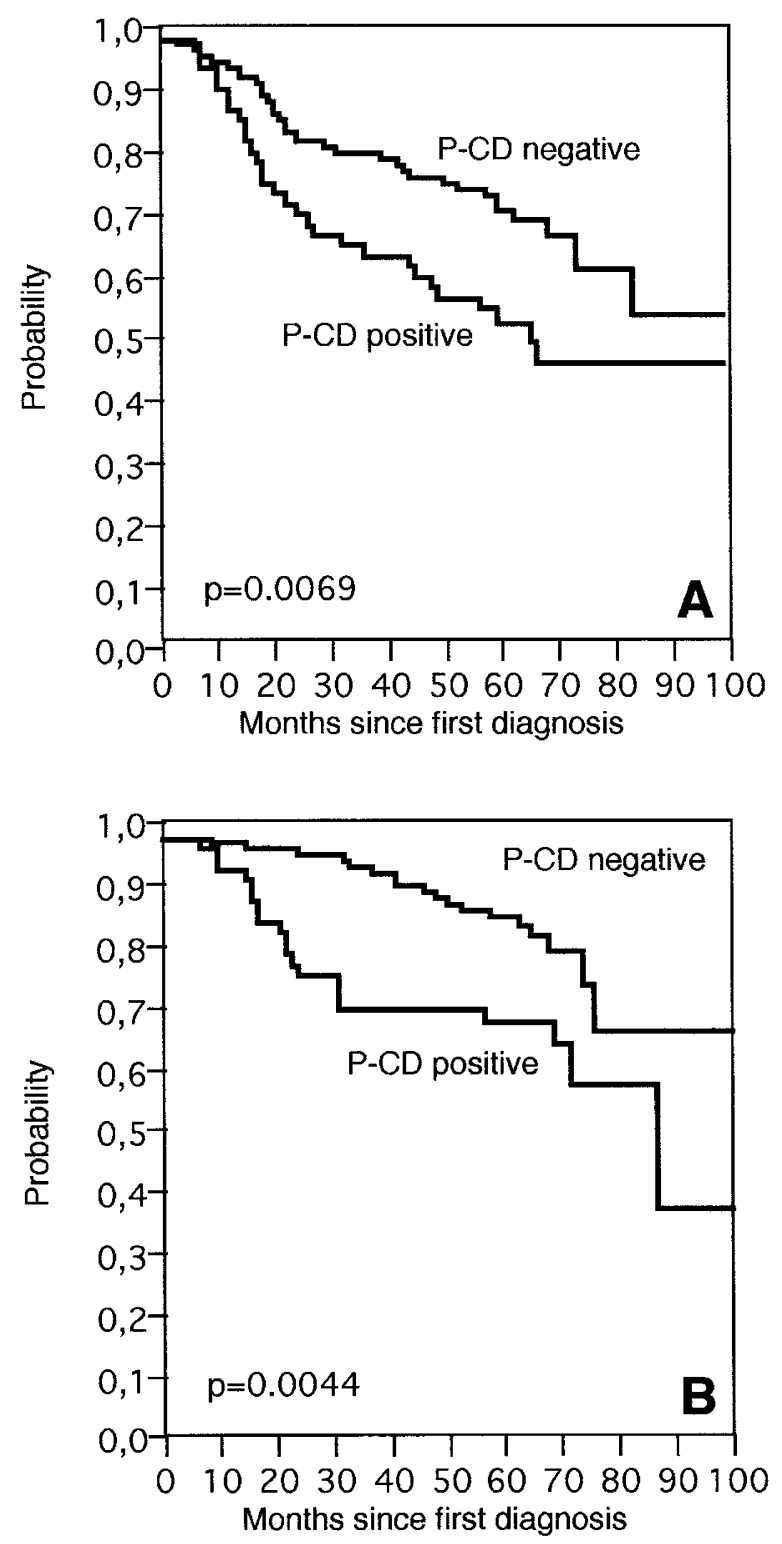

FIGURE 2. Kaplan-Meier curves showing probability of disease-free survival (A) and overall survival (B) for patients with P-cadherin-positive tumors versus patients with P-cadherin-negative tumors (log-rank test). 
as previously reported (4-6). The biological significance of P-CD expression in IDCs is poorly understood. We have previously demonstrated that P-CD expression in breast tumors is not related to myoepithelial phenotype (5). It has been suggested that the anomalous expression of P-CD in breast cancer cells might represent the acquisition of an embryonic phenotype similar to that of cap cells, which are high-proliferative, E-CD negative, ER negative, and P-CD positive (5). The results of the present study support this hypothesis and suggest that P-CD expression could also be considered to constitute a marker of breast cancer progression, because P-CD expression was present more frequently in larger, poorly differentiated, hormonereceptor-negative and E-CD-negative tumors with greater numbers of lymph node metastases.

The present study did not confirm the finding of a previous report in which P-CD expression appeared to be an independent prognostic factor in breast cancer (6). Although we observed shorter disease-free survival and overall survival time periods in IDC with P-CD expression in the univariate analysis, the multivariate analysis only selected lymph node metastasis and histological grade as independent prognostic factors. Differences in follow-up period could explain the differences between our study and that of Peralta Soler et al. (6), because these authors analyzed survival after 5 years. In our cohort, differences in survival between P-CD-positive and -negative tumors were more evident at 5 years in the Kaplan-Meier curves, suggesting that although P-CD expression could be a predictor of poor prognosis at 5 years, it loses its prognostic value in long-term follow-up studies. Another important difference between the two studies was sample selection, because the study of Peralta Soler et al. (6) included tumors of different histological types (ductal lobular, medullary, and metaplastic). P-CD expression is related to the histological type of breast carcinomas. Some special histological types such as colloid, papillary, or lobular $(4,5)$ tend to be P-CD negative, whereas most medullary and metaplastic breast carcinomas are P-CD positive (17).

In the current study, we found that $35 \%$ of IDCs analyzed expressed P-CD in $>5 \%$ of tumor cells. This frequency is in contrast to that reported by Peralta Soler et al. (6), who found that around $60 \%$ of IDCs expressed P-CD. However, the immunohistochemistry methodology was similar in both studies, because the same monoclonal antibody and an antigen retrieval step were used. In addition, all tumor sections included in this study had normal breast tissue with myoepithelial cells, which served as a positive internal control. The difference in P-CD expression frequency between both series was probably also related to sample selection, because tumors in Peralta-Soler's series were selected on the basis of their large size, whereas in the current group, nearly $40 \%$ of the tumors were T1. This fact could explain not only the differences in the frequency of P-CD expression among series, but also our finding of a relationship between tumor size and P-CD expression, which was not found in the study of Peralta Soler et al.

Although studies of P-CD expression in breast cancer are scarce, many studies have analyzed E-CD expression in such tumors. Most of them have reported an association between E-CD expression and histological type and differentiation. However, the relationship between E-CD expression and lymph node metastases and survival remains controversial $(6,15,18-24)$. As has been suggested, contradictory results probably reflect the difficulty of evaluating decreased protein expression in tumor cells, which need not only optimal tissue processing but also a homogeneous system in order to be evaluated (6). A relationship between P-CD expression and reduced E-CD expression has been observed in the present and previous studies $(5,6)$, suggesting that $\mathrm{E}-$ and $\mathrm{P}-\mathrm{CD}$ might be regulated in a contrary manner. In breast cancer, although several mechanisms, such as gene mutation, gene promoter hypermethylation, or disruption of the cadherin-catenin complex (25), appear to be responsible for down-regulation or loss of expression of E-CD, they apparently cannot explain why P-CD is up-regulated in some cases. Regulation of both Eand P-CD in tumor tissue may involve a specific transcriptional mechanism, because E- and P-CD genes are both located at $16 q 22$ and contain promoter with similar putative regulatory elements (13). Interestingly, P-CD expression in the current and previous series $(5,6)$ is associated with negative estrogen and progesterone receptors, whereas E-CD expression is associated with positive estrogen and progesterone receptors. It is well known that estrogens are capable of stimulating E-CD expression (26) and that the promoter region of the mouse E-CD gene contains progesteroneresponsive elements (27). It is possible that $\mathrm{P}-\mathrm{CD}$ expression in breast carcinomas is related to a phenotype that is insensitive to circulating hormones, as has been suggested in the case of prostate cancer where P-CD and PSA expression are mutually exclusive in tumor cells (14).

In conclusion, the results of the current study indicate that although P-CD expression occurs more frequently in poorly differentiated, hormone receptor-negative, lymph node-positive infiltrating ductal carcinomas, its value as an independent prognostic factor remains to be established. 
Acknowledgments: We thank Ginesa García Rostan for comments on the manuscript.

\section{REFERENCES}

1. Shimoyama Y, Hirohashi S, Hirano S, Noguchi M, Shimosato $\mathrm{Y}$, Takeichi M, et al. Cadherin cell-adhesion molecules in human epithelial tissues and carcinomas. Cancer Res 1989; 49:2128-33.

2. Takeichi M. Cadherin cell adhesion receptors as a morphogenetic regulator. Science 1991;251:1451-5.

3. Johnson KR, Lewis JE, Li D, Wahl J, Soler AP, Knudsen KA, et al. $\mathrm{P}$ - and E-cadherin are in separate complexes in cells expressing both cadherins. Exp Cell Res 1993;207:252-60.

4. Rasbridge SA, Gillett CE, Sampson SA, Walsh FS, Millis RR. Epithelial (E-) and placental (P-) cell adhesion molecule expression in breast carcinoma. J Pathol 1993;169:245-50.

5. Palacios J, Benito N, Pizarro A, Suárez A, Espada J, Cano A, et al. Anomalous expression of P-cadherin in breast carcinoma. Correlation with E-cadherin expression and pathological features. Am J Pathol 1995;46:605-12.

6. Peralta Soler A, Knudsen KA, Salazar H, Han A, Keshgegian AA. P-cadherin expression in breast carcinoma indicates poor survival. Cancer 1999;86:1263-72.

7. Daniel CW, Strickland P, Friedmann Y. Expression and functional role of E- and P-cadherins in mouse mammary ductal morphogenesis and growth. Dev Biol 1995;169:511-9.

8. Radice GL, Ferreira-Cornwell MC, Robinson SD, Rayburn H, Chodosh LA, Takeichi M, et al. Precocious mammary gland development in P-cadherin-deficient mice. J Cell Biol 1997; 139:1025-32.

9. Sanders DSA, Perry I, Hardy R, Jankowski J. Aberrant $\mathrm{P}$-cadherin expression is a feature of clonal expansion in the gastrointestinal tract associated with repair and neoplasia. J Pathol 2000;190:526-30.

10. Shimoyama Y, Hiroshasi S. Expression of E- and P-cadherin in gastric carcinomas. Cancer Res 1991;51:2185-92.

11. Yasui Y, Sano T, Nishimura Y, Kitadi Y, Ji ZQ, Yokozaki H, et al. Expression of P-cadherin in gastric carcinoma and its reduction in tumor progression. Int J Cancer 1993;54:49-52.

12. Pizarro A, Gamallo C, Benito N, Palacios J, Quintanilla M, Cano A, et al. Differential patterns of placental and epithelial cadherin xpression in basal cell carcinoma and in the epidermis overlying tumors. Br J Cancer 1995;72:327-32.

13. Jarrard DF, Paul R, van Bokhoven A, Nguyen SH, Bova GS, Wheelock MJ, et al. P-cadherin is a basal cell-specific epithelial marker that is not expressed in prostate cancer. Clin Cancer Res 1997;3:221-8.

14. Peralta Soler A, Harner GD, Knudsen KA, McBearty FX, Grujic E, Salazar $\mathrm{H}$, et al. The expression of P-cadherin identifies
PSA negative cells in epithelial tissues of male sexual accessory organs and in prostatic carcinomas. Implications for prostate cancer biology. Am J Pathol 1997;151:471-8.

15. Gamallo C, Palacios J, Benito N, Limeres MA, Pizarro A, Suárez A, et al. Expression of E-cadherin in 230 infiltrating ductal breast carcinomas: relationship to clinicopathological features. Int J Oncol 1996;9:1207-2.

16. Elston CW. Grading of invasive carcinoma of the breast. In: Page DL, Anderson TJ, editors. Diagnostic histopathology of the breast. Edinburgh, United Kingdom: Churchill Livingstone; 1987: 300-11.

17. Han AC, Peralta Soler A, Knudsen KA, Salazar H. Distinct cadherin profiles in special variant carcinomas and other tumors of the breast. Hum Pathol 199;30:1035-9.

18. Gamallo C, Palacios J, Suarez A, Pizarro A, Navarro P, Quintanilla M. Correlation of E-cadherin expression with differentiation grade and histological type in breast carcinoma. Am J Pathol 1993;142:987-93.

19. Oka H, Shiozaki H, Kobayashi K, Inoue M, Tahara H, Kobayashi $\mathrm{T}$, et al. Expression of E-cadherin cell adhesion molecules in human breast cancer tissues and its relationships to metastasis. Cancer Res 1993;53:1696-701.

20. Hunt NC, Douglas-Jones AG, Jasani B, Morgan JM, Pignatelli M. Loss of E-cadherin expression associated with lymph node metastases in small breast carcinomas. Virchows Arch 1997;430:285-9.

21. Charpin C, García S, Bonnier P, Martini F, Andrac L, Choux $\mathrm{R}$, et al. Reduced E-cadherin immunohistochemical expression in node-negative breast carcinomas correlates with 10year survival. Am J Clin Pathol 1998;109:431-8.

22. Tan DS, Potts HW, Leong AC, Gillet CE, Skilton D, Harris $\mathrm{WH}$, et al. The biological and prognostic significance of cell polarity and E-cadherin in grade I infiltrating ductal carcinomas of the breast. J Pathol 1999;189:20-7.

23. González MA, Pinder SE, Wencyk PM, Bell JA, Elston CW, Nicholson RI, et al. An immunohistochemical examination of the expression of E-cadherin, alpha- and beta/gamma catenins, and alpha- 2 and beta- 1 integrins in invasive breast cancer. J Pathol 2000;187:523-9.

24. Heimann R, Lan F, McBride R, Hellman S. Separating favorable from unfavorable prognostic markers in breast cancer: the role of E-CD. Cancer Res 2000;60:298-304.

25. Hiraguri S, Godfrey T, Nakamura H, Graff J, Collins C, Shayesteh L, et al. Mechanisms of inactivation of E-cadherin in breast cancer cell lines. Cancer Res 1998;58:1972-7.

26. Blaschuk OW, Munro SB, Farookhi R. Cadherins, steroid and cancer. Endocrine 1995;3:83-9.

27. Ringwald M, Baribault H, Schmidt C, Kemler R. The structure of the gene coding for the mouse cell adhesion molecule uvomorulin. Nucleic Acids Res 1991;19:6533-9. 